\title{
Caracterización de la cadena de valor del maíz
}

\author{
Francisca Santana Robles[a], Rafael Granillo Macías[a], Frida Ivonne Espinoza Sánchez[b], \\ Juan Carlos Aguilar Ortega ${ }^{[b]}$, José Guadalupe Ortega Zavala[b] \\ [a] Profesor Investigador de la Escuela Superior de Ciudad Sahagún de la Universidad Autónoma del Estado de Hidalgo \\ [b] Estudiante de la Licenciatura en Ingeniería Industrial en la Escuela Superior de Ciudad Sahagún de la Universidad \\ Autónoma del Estado de Hidalgo
}

\section{RESUMEN}

El maíz es uno de los principales cultivos a nivel mundial debido a su importancia en el consumo humano, alimentación de ganado y uso industrial. Sin embargo, presenta grandes retos debido a la escasez de recursos para su cultivo; además, existe la necesidad de nuevas herramientas y métodos para poder mejorar su rendimiento. En este trabajo, se realiza un análisis del comportamiento de la producción a nivel mundial y nacional; además, se identifican los eslabones que conforman la cadena de valor, así como atributos de sustentabilidad y gobernanza. La metodología utilizada es descriptiva con enfoque cualitativo, con información obtenida de fuentes nacionales e internacionales.

Palabras clave: maíz, cadena de valor, gobernanza, sustentabilidad.

\begin{abstract}
Maize is one of the main crops worldwide due to its importance in human consumption, livestock feed and industrial use. However, it presents great challenges due to the scarcity of resources for its cultivation; in addition, there is a need for new tools and methods to improve performance. In this work, an analysis of the production behavior at the global and national level is carried out; In addition, we identify the links that make up the value chain, as well as attributes of sustainability and governance. The methodology used is descriptive with a qualitative approach, with information obtained from national and international sources.
\end{abstract}

Keywords: corn, value chain, governance, sustainability. 


\section{INTRODUCCIÓN}

En la actualidad el sector agroalimentario enfrenta grandes retos, debido a factores como: escasez de tierra y agua para la agricultura y rendimientos decrecientes en los cultivos. Esto ha originado escases de alimentos de origen agrícola, así como aumento en el costo de producción de los mismos. Además, debido a que este tipo de alimento es la base de la alimentación de la población a nivel mundial, organismos como el Banco Mundial han incrementado las inversiones en dicho sector.

Por otro lado, el maíz es uno de los principales cereales cultivados a nivel mundial debido a sus cualidades alimenticias para la producción de proteína animal, el consumo humano y uso industrial; por lo que, es representativo en el mercado mundial (FIRA, 2016).

En el contexto nacional, el maíz es el cultivo agrícola más importante desde el punto de vista alimentario, industrial, político y social. Se produce en dos ciclos productivos: primavera-verano (PV) y otoño-invierno (OI), bajo las más diversas condiciones agroclimáticas (humedad, temporal y riego) y diferentes tecnologías (Deere, 2016). México ocupa el séptimo lugar como productor de maíz grano (SAGARPA, 2016). Sin embargo, no es autosuficiente; puesto que depende de las importaciones para poder hacer frente a la demanda. Estados Unidos (EE.UU.) es el principal exportador representando el 98 por ciento de las importaciones.

Por otro lado, de acuerdo a Porter (1985) la cadena de valor (CV) es un conjunto de actividades que se desarrollan para diseñar, producir, vender, enviar y dar soporte al producto. La CV de una empresa y la forma cómo ésta funciona es un reflejo de su historia, de su estrategia y su enfoque para implementar dicha estrategia. Las actividades desempeñadas se agrupan en dos categorías: actividades primarias y secundarias. La primera categoría la componen las actividades: compras, logística de entrada, fabricación, logística de salida, mercadotecnia y ventas, servicio. La segunda categoría la componen las actividades de apoyo como: infraestructura de la empresa, administración de recursos humanos, administración de la cadena de valor, tecnología de la información, desarrollo tecnológico, administración de la demanda y administración financiera corporativa.

De acuerdo a Kaplinsky y Morris (2000) la cadena de valor alimentaria sostenible está formada por todas las partes (explotaciones agrícolas y empresas), así como todas las actividades que se realizan de manera integrada para agregar valor a la producción, transformación y distribución de productos de agrícolas; permitiendo que cada eslabón de la cadena sea un proceso rentable y proporcione amplios beneficios para la sociedad, además del uso limitado de los recursos naturales.

Dentro de la CV se distinguen cuatro funciones básicas (eslabones o fases): producción, agrupamiento, elaboración y distribución. La función de agrupamiento (acopio y 
almacenamiento) la pueden llevar acabo grupos de productores, intermediarios especializados en agrupamiento y fabricantes de alimentos (Neven, 2015).

La estructura de gobernanza de la $\mathrm{CV}$ es un elemento fundamental. "El término gobernanza se refiere a la naturaleza de los vínculos entre actores en ciertas etapas de la cadena (vínculos horizontales) y dentro de la cadena en general (vínculos verticales). También contempla elementos como el intercambio de información, determinación de precios, las normas, los sistemas de pago, los contratos con o sin servicios incluidos, el poder de mercado, las principales empresas y los sistemas de mercado al por mayor" (Neven, 2015).

De acuerdo a Gereffi, Humphrey y Sturgeon (2005) existen cinco tipos de gobernanza de CV (jerárquica, captiva, relacional, modular y mercado). La gobernanza jerárquica tiene como característica la integración vertical, la forma de dominio es de control gerencial, fluye desde administradores hacia subordinados o desde oficinas centrales hacia filiales. La CV captiva, en este tipo de red las transacciones de los proveedores pequeños dependen en gran medida de grandes compradores, los proveedores se enfrentan a costosos cambios significativos. Estas redes son frecuentemente caracterizadas por un alto grado de monitoreo y control de empresas líderes. Asimismo, la CV relacional es una red con interacciones complejas entre proveedores y compradores que frecuentemente crean dependencia mutua y altos niveles de especificidad de bienes; puede ser administrada a través de la reputación, familias o lazos étnicos. La CV modular, los proveedores en esta cadena fabrican productos de acuerdo a especificaciones de los clientes que pueden ser más o menos detallados, sin embargo los proveedores toman total responsabilidad por la competencia, usan maquinaria genérica que limita las inversiones de transacción específicas y hacen desembolso de capital para componentes y materiales a favor de los clientes. En la CV de mercado, los eslabones de mercado no tienen que ser transitorios completamente, ellos pueden persistir en el tiempo, con transacciones repetidas. El punto esencial es que los costos de cambio hacia los nuevos socios son bajos para ambos.

Gereffi, Humphrey y Sturgeon (2005) distinguieron algunos criterios para construir una teoría de gobernanza de la $\mathrm{CV}$ : complejidad de información y conocimiento necesario para una transacción particular con respecto a las especificaciones de un producto y proceso; la extensión a la que esta información y conocimiento puede ser codificado y transmitido de manera eficiente entre las partes; las capacidades de proveedores actuales y potenciales en relación a los requerimientos de la transacción.

El presente trabajo tiene como objetivo caracterizar la CV del maíz considerando aspectos de producción a nivel mundial y nacional, así como la estructura de gobernanza de la CV antes mencionada. La metodología utilizada es descriptiva con enfoque cualitativo, debido a que la información se obtuvo a través de una investigación documental con información bibliográfica, bases de datos de organismos nacionales e internacionales, así como datos de fuente secundaria de resultados de estudios previos del sector agroalimentario. 


\section{El maíz en el contexto mundial}

Actualmente, el maíz es el segundo cultivo más importante en el mundo por su producción, después del trigo, mientras que el arroz ocupa el tercer lugar. El maíz es de gran importancia económica a nivel mundial, ya sea como alimento humano, alimento para ganado o como fuente de un gran número de productos industriales. De acuerdo con la Secretaría de Economía (SE, 2012) en los últimos años, debido a los avances en conocimientos científicos y tecnológicos aplicados al estudio del maíz, se puede obtener una gran variedad de productos, los principales son: proteínas para la elaboración de alimentos balanceados; dextrosa para botanas, panificación, bebidas, sueros, lisina, ácido cítrico y antibióticos; etanol para la elaboración de alcoholes industriales, bebidas alcohólicas y combustibles; jarabe de alta fructuosa como edulcorante para la elaboración de refrescos, jugos, mermeladas, dulces, postres, vinos y endulzantes de bajas calorías; aceites de uso doméstico y alimentos para bebé; almidón para la elaboración de pan, atole, alimentos infantiles, cerveza y papel; glucosa para la fabricación de dulces, caramelos y chicles; colorante en los procesos para la elaboración de refrescos, cerveza, licores, embutidos y panificación; maltodextrinas para la elaboración de leche en polvo, embutidos; y sorbitol para pastas de dientes y confitería.

Por otro lado, según cifras de la División de Estadística de la Organización de las Naciones Unidas (FAOSTAT, por sus siglas en inglés) se ha observado un aumento en la producción del maíz en la última década, principalmente en el año 2013 donde se originó un aumento de 18.11 por ciento con respecto al año anterior (véase Tabla 1 y Figura 1). Además, los principales productores a nivel mundial son EE.UU., China y Brasil como puede observarse en la Tabla 2. Donde EE.UU. supera por mucho a los otros dos países, puesto que, desde el año 2010 hasta 2014 ha mantenido una producción mayor al 40 por ciento; por otro lado, China se ha mantenido en una producción del 26 al 30 por ciento de la producción mundial. Las Figuras 2, 3 y 4 muestran el comportamiento de la producción del maíz de los principales países en los años 2012, 2013 y 2014 (FAOSTAT, 2017).

De acuerdo a International Service for the Acquisition of Agri-biotech Aplications (ISAAA, 2015) EE.UU., Brasil y Argentina plantaron más del 77 por ciento de los cultivos transgénicos del mundo en el año 2015, cubriendo una superficie mundial de 179.7 millones de hectáreas, de las que 70.9 millones se cultivaron en EE.UU., 44.2 millones en Brasil, 24.5 millones en Argentina, 11.6 millones en India y 11 millones en Canadá. En el caso de EE.UU., dichos cultivos pertenecen a maíz, soya, algodón, canola, betabel, alfalfa, papaya, chayote y papa; sin embargo, de acuerdo a datos oficiales el 60 por ciento de la producción total de maíz es genéticamente modificado. Mientras que, para los casos de Brasil y Argentina los cultivos pertenecen a soya, maíz y algodón. 
Tabla 1. Producción de maíz a nivel mundial

(cifras expresadas en toneladas)

\begin{tabular}{|c|c|c|c|c|c|}
\hline & 2010 & 2011 & 2012 & 2013 & 2014 \\
\hline $\begin{array}{c}\text { Producción } \\
\text { mundial de maíz }\end{array}$ & 671105936 & 687793578 & 679041461 & 802080296 & 812900098 \\
\hline
\end{tabular}

Fuente: elaborado con información de (FAOSTAT, 2017).

Figura 1. Comportamiento de la producción de maíz a nivel mundial

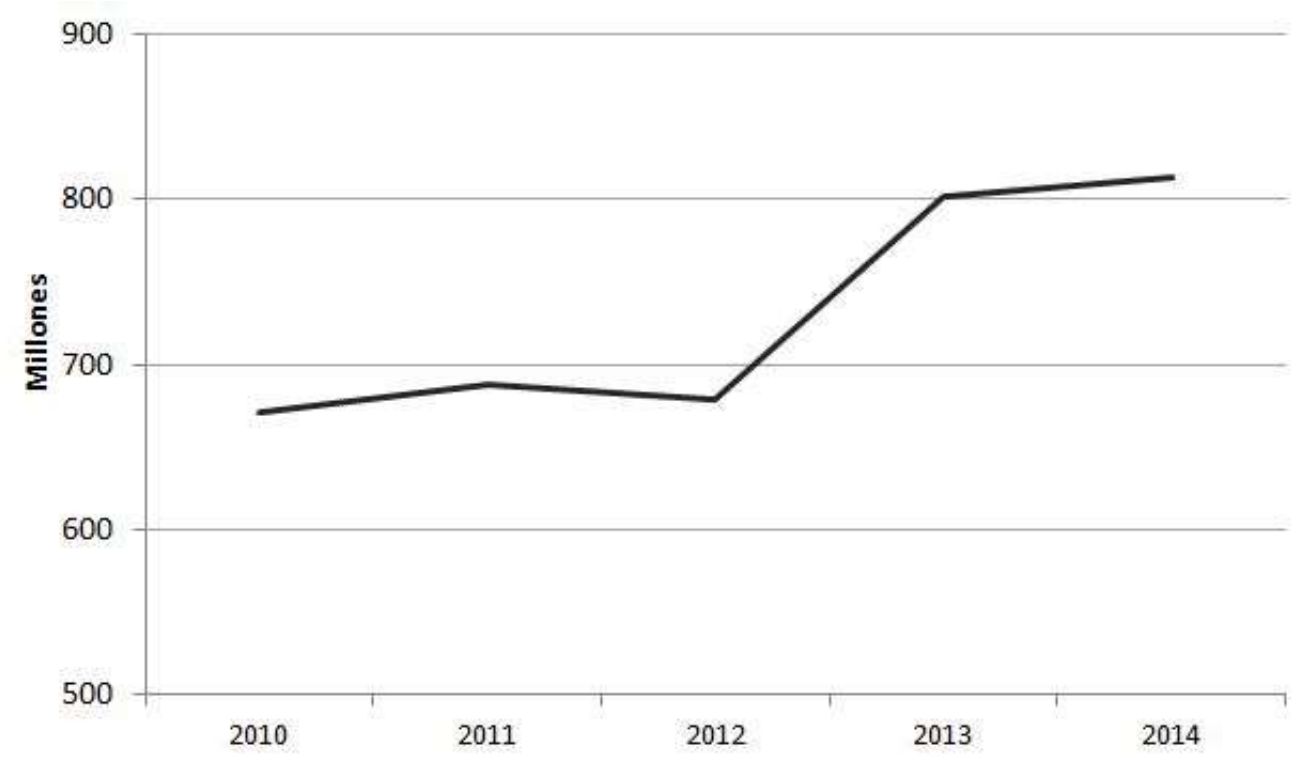

Fuente: elaborado con información de (FAOSTAT, 2017).

Tabla 2. Principales países productores de maíz a nivel mundial

(cifras expresadas en toneladas)

\begin{tabular}{|l|l|l|l|l|l|l|l|}
\hline \multirow{2}{*}{ Ranking } & & 2010 & 2011 & 2012 & 2013 & 2014 \\
\cline { 5 - 8 } & Productores & \multicolumn{4}{|c|}{ Producción en toneladas } \\
\hline 1 & $\begin{array}{l}\text { Estados Unidos } \\
\text { de América }\end{array}$ & 316164930 & 313934773 & 273820066 & 351271870 & 361091140 \\
\hline 3 & China & 177540788 & 192904232 & 205719284 & 218621905 & 215812100 \\
\hline 4 & Brasil & 55364271 & 55660235 & 71072810 & 80273172 & 79881614 \\
\hline 5 & México & 23301879 & 17635417 & 22069254 & 22663953 & 23273257 \\
\hline 6 & Argentina & 22663095 & 23799830 & 21196637 & 32119211 & 33087165 \\
\hline
\end{tabular}




\begin{tabular}{|l|l|l|l|l|l|l|}
\hline 7 & Sudáfrica & 12815000 & 10360000 & 12120656 & 11810600 & 14250000 \\
\hline 8 & Ucrania & 11953000 & 22837900 & 20961300 & 30949550 & 28496810 \\
\hline 9 & Canadá & 11714500 & 10688700 & 13060100 & 14193800 & 11486800 \\
\hline 10 & Nigeria & 7676850 & 8878456 & 8694900 & 8422670 & 10790600 \\
\hline 11 & Serbia & 7207191 & 6479564 & 3532602 & 5864419 & 7951583 \\
\hline 12 & Filipinas & 6376796 & 6971221 & 7406830 & 7377293 & 7770603 \\
\hline
\end{tabular}

Fuente: elaborado con información de (FAOSTAT, 2017).

Figura 2. Producción de maíz de los principales países productores en 2012.

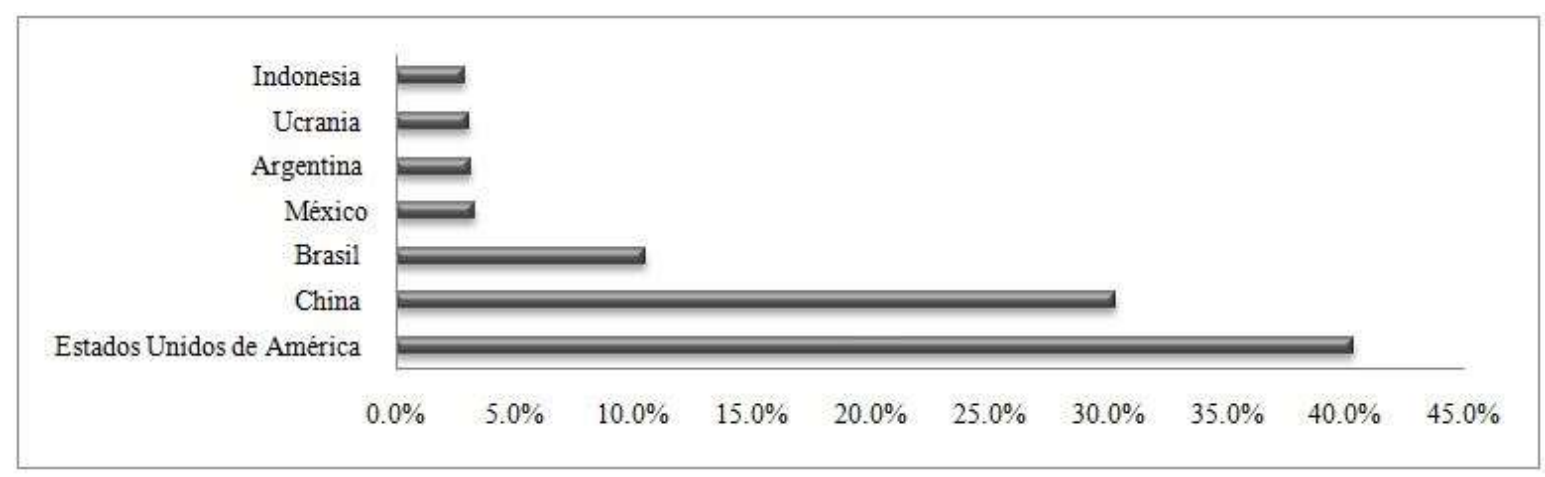

Fuente: elaborado con base en (FAOSTAT, 2017).

Figura 3. Producción de maíz de los principales países productores en 2013.

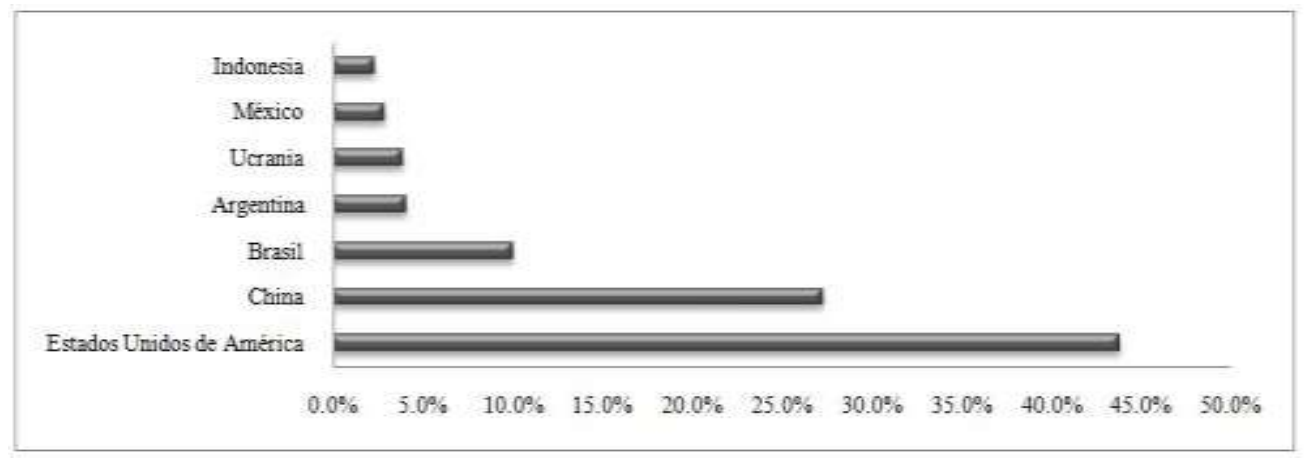


Fuente: elaborado con base en (FAOSTAT, 2017).

Figura 4. Producción de maíz de los principales países productores en 2014.

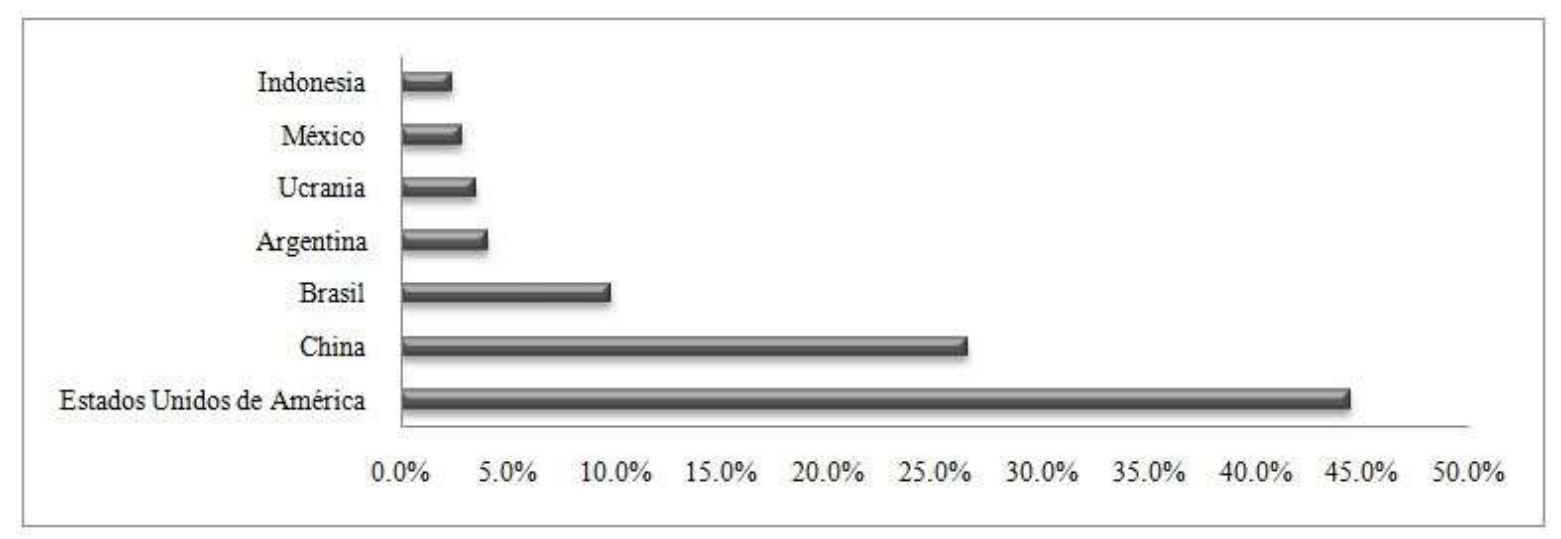

Fuente: elaborado con base en (FAOSTAT, 2017).

Por otro lado, el pronóstico de producción mundial de maíz para los años 2017 y 2018 son de 872487472 y 899591768 toneladas, respectivamente, véase Figura 5. Asimismo, el pronóstico de producción para EE.UU. es de 359740545 y 365880482 toneladas; para China es de 247329929 y 256515430 toneladas para los años 2017 y 2018. De acuerdo a SAGARPA (2011) se espera que la demanda del maíz para la producción del etanol en EE.UU. mantenga un nivel elevado con crecimiento moderado. Además, se estima un crecimiento en el consumo y en el comercio exterior de granos y oleaginosas. Se prevé que el 36 por ciento de la demanda total de maíz se utilice en la producción de etanol. 
Figura 5. Pronóstico de producción mundial de maíz

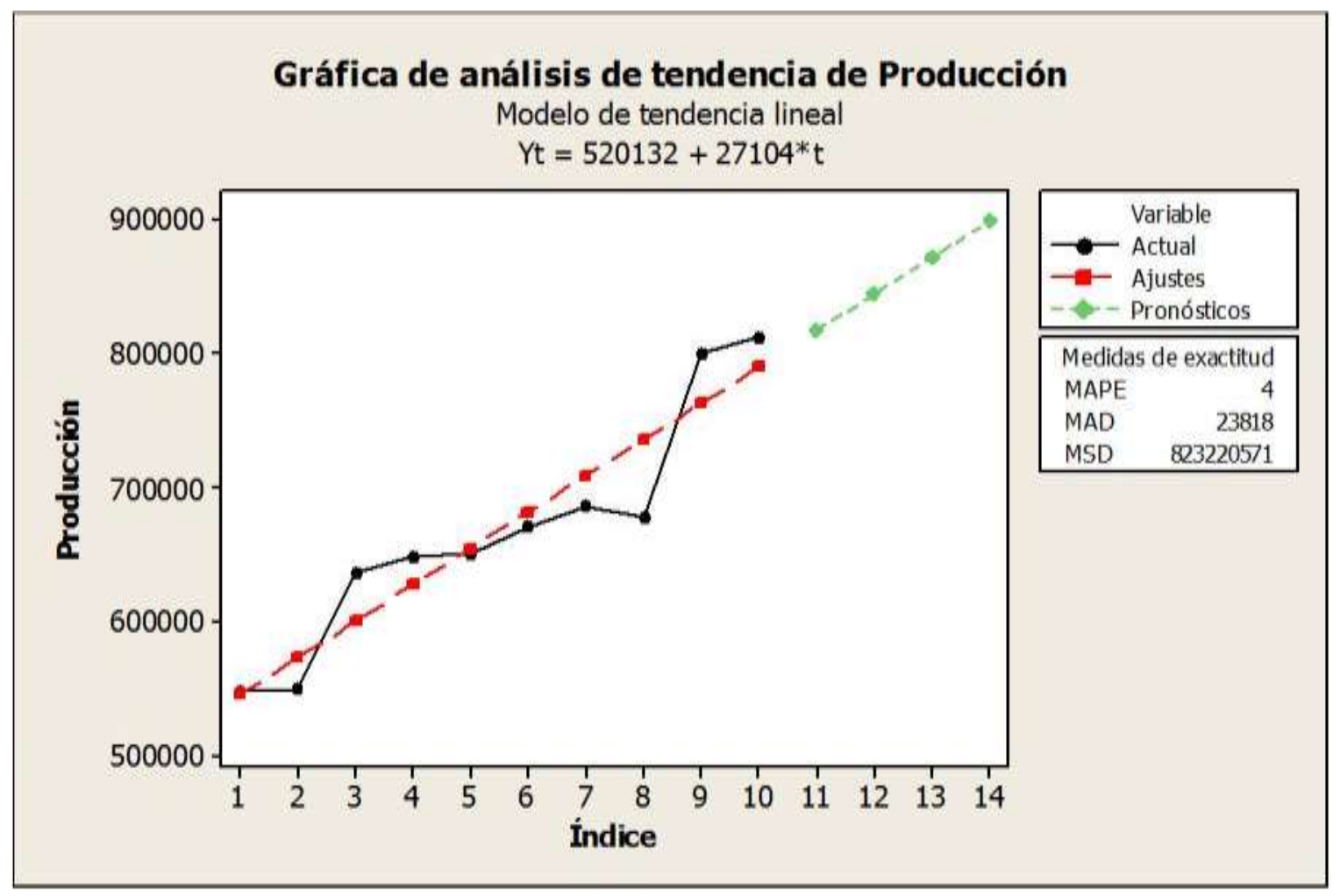

Fuente: elaborado con información de (FAOSTAT, 2017).

\section{El maíz en el contexto nacional}

De acuerdo a (SAGARPA, 2016) México ocupa el séptimo lugar como productor de maíz grano (SAGARPA, 2016). Asimismo, es el principal productor de maíz blanco en el mundo, y representa el 35 por ciento de la superficie sembrada durante un año agrícola. Por otro lado, la producción de maíz amarillo representa aproximadamente el 5 por ciento de la producción nacional. El mercado nacional de maíz grano se encuentra en un periodo de recuperación después de registrar el volumen de producción más bajo de los últimos 10 años durante 2011. Además, el consumo de maíz continúa en aumento, y con ello el aumento de las importaciones; durante el año 2014 aumentaron 45.7 por ciento en relación a 2013 (FIRA, 2015). El consumo fue valorado en 35.6 millones de toneladas durante el año agrícola 2015, lo que representa un incremento del 7.2 por ciento en relación al año agrícola 2014, del cual el 64 por ciento corresponde a maíz blanco y el 36 por ciento a maíz amarillo. En este contexto, la tabla 3 y la figura 6 muestran una recuperación de la producción pasando de 17635417 a 24694046 de los años 2011 a 2015, respectivamente. Representando un porcentaje de 40 por ciento. 
Tabla 3. Producción de maíz a nivel nacional

(cifras expresadas en toneladas)

\begin{tabular}{|l|l|l|l|l|l|l|}
\hline & 2010 & 2011 & 2012 & 2013 & 2014 & 2015 \\
\hline $\begin{array}{l}\text { Producción } \\
\text { nacional }\end{array}$ & $\mathbf{2 3 , 3 0 1 , 8 7 8}$ & $\mathbf{1 7 , 6 3 5 , 4 1 7}$ & $\mathbf{2 2 , 0 6 9 , 2 5 4}$ & $\mathbf{2 2 , 6 6 3 , 9 5 3}$ & $\mathbf{2 3 , 2 7 3 , 2 5 6}$ & $\mathbf{2 4 , 6 9 4 , 0 4 6}$ \\
\hline
\end{tabular}

Fuente: elaborado con información de (SIAP, 2017).

Figura 6. Producción de maíz a nivel nacional, en toneladas.

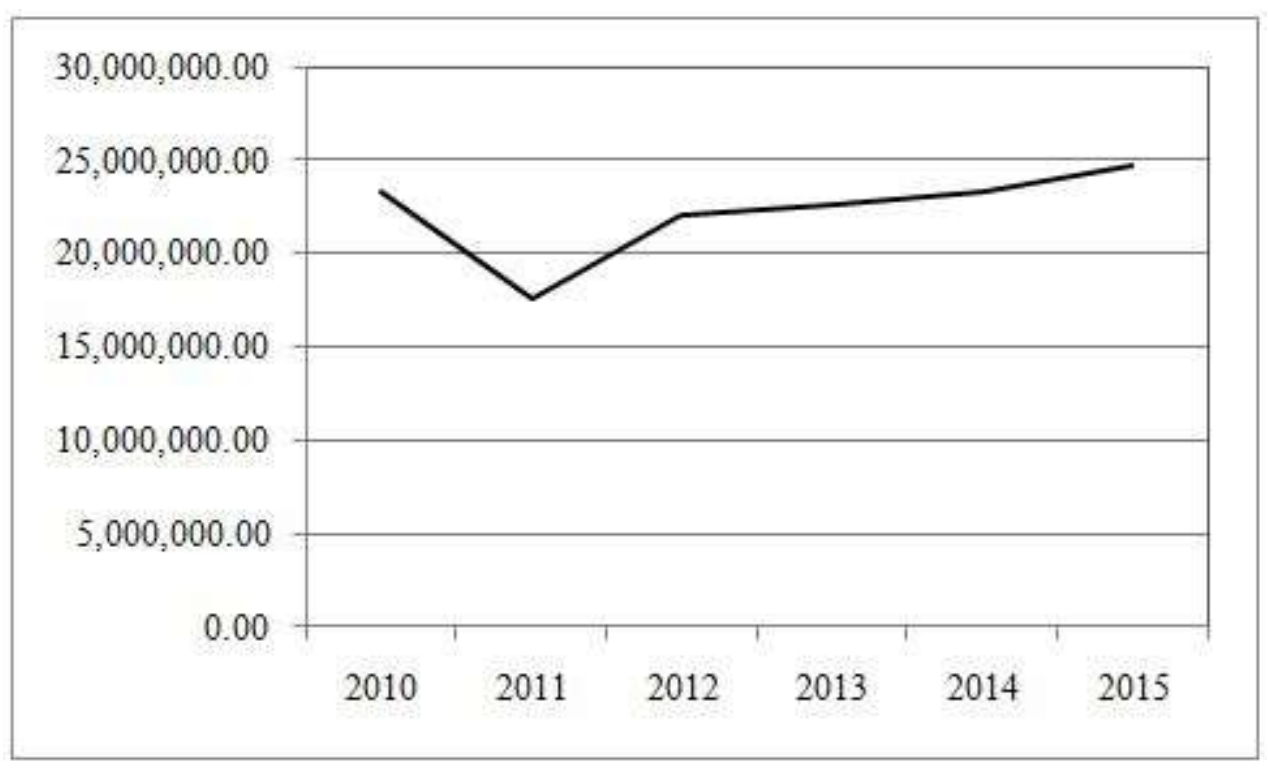

Fuente: elaborado con información de (SIAP, 2017).

Por otro lado, los estados más representativos como productores de maíz son Sinaloa, Jalisco, Michoacán y Estado de México, como se muestra en las figuras 7 y 8 . Para el año 2014 estos cuatro estados obtuvieron el 47 por ciento de la producción de maíz a nivel nacional, representando un total de 10949938 toneladas. Cabe destacar que los estados de Guanajuato, Chihuahua, Guerrero, Veracruz, Chiapas y Puebla también representativos, representando el 32\% de la producción en 2014. En el mismo contexto, para el año 2015 los 
diez estados mencionados anteriormente representaron el 75 por ciento de la producción nacional, equivalente a 18557525 toneladas.

Figura 7. Producción de maíz de los principales estados productores en 2014.

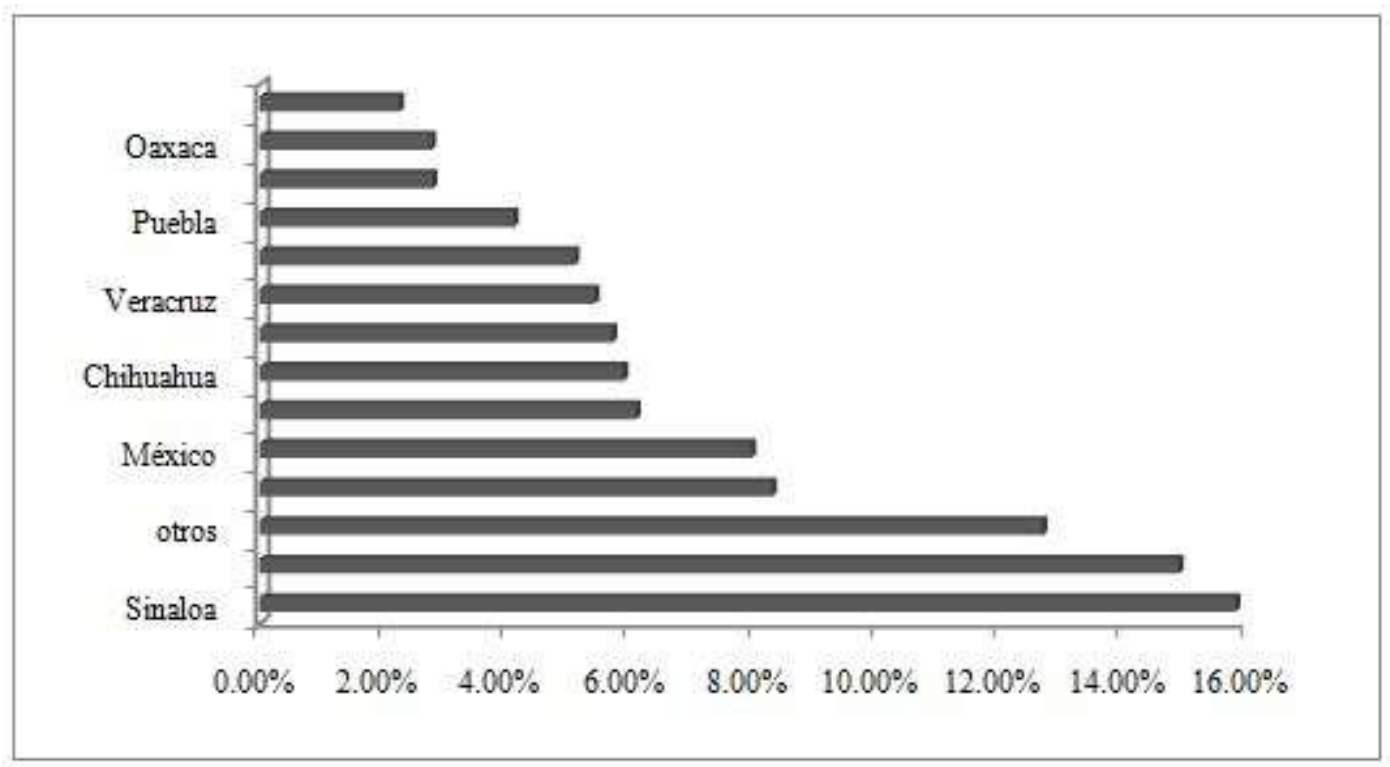

Fuente: elaborado con base a (SIAP, 2017).

Figura 8. Producción de maíz de los principales estados productores en 2015.

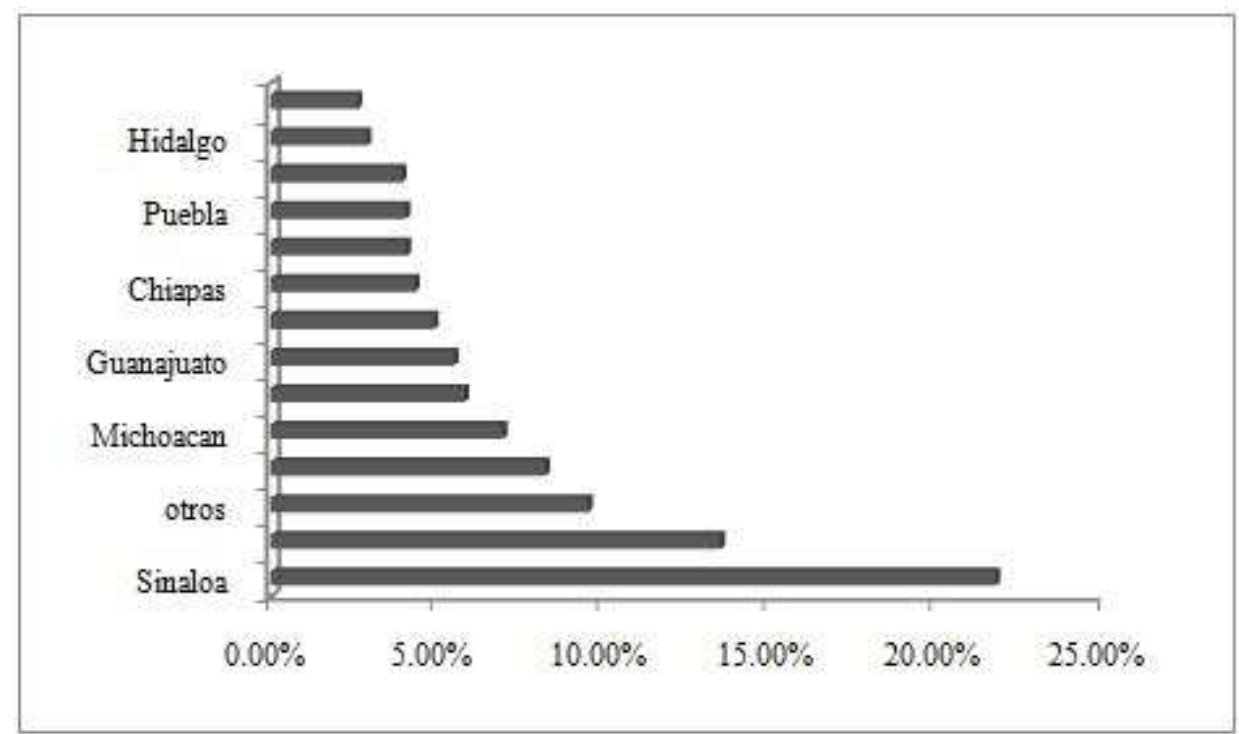

Fuente: elaborado con base a (SIAP, 2017). 
En este contexto, México no ha sido representativo en la producción de maíz amarillo, por lo cual, actualmente es uno de los mayores importadores a nivel mundial de esta clase de maíz. Utilizándolo principalmente para el sector pecuario, ocupando un $54 \%$ de las importaciones de maíz amarillo; en segundo lugar, se ubica el sector almidonero con 36\%, después el sector de la harina con el $6 \%$ y finalmente los sectores de cereales y botanas que ocupan el $2 \%$ cada uno (Deere, 2016).

\section{Autoconsumo}

La producción de autoconsumo se relaciona con el minifundio. Se basa en el uso intensivo de la mano de obra familiar. Los estados con este sistema son Chiapas, Guerrero, Hidalgo, Estado de México, Morelos, Puebla, Oaxaca, Veracruz y Yucatán, entre los más importantes. Estas zonas productoras de autoconsumo presentan una correlación estrecha con las regiones de alta marginación y pobreza del país (SAGARPA, 2013). El autoconsumo en México se basa en la elaboración de alimentos como lo son los tamales, las tortillas, atoles de masa o de grano, elotes en algunas ocasiones suele ser empleado como forraje.

\section{Caracterización de la cadena de valor}

Dentro de la CV del maíz participan diferentes actores que hacen que sea posible la producción y comercio del maíz, de los cuales destacan (Fretes y Martínez, 2011):

- Proveedores de servicios: son instituciones públicas o privadas que prestan diversos tipos de servicio, brindando apoyos para la adquisición de semilla, primas de seguros, asistencia técnica y de gestión en la celebración de contratos de comercialización, permitiendo la compra de cosechas en condiciones justas tanto para los productores como para los compradores de maíz.

- Proveedores de insumos, maquinarias y equipos: son empresas públicas o privadas que promueven diversos insumos para el cultivo como fertilizantes, agroquímicos, maquinaria o herramientas, así como también brindan asesorías técnicas para su uso y mantenimiento.

Productor: representa el principal eslabón de la $\mathrm{CV}$, existiendo tres tipos de productores como los son:

Microproductor: son aquellos que cultivan para consumo y comercialización a mercados locales. Representa el elemento de la cadena más vulnerable.

Pequeño y mediano productor: orienta su cultivo a clientes determinados. Adapta la tecnología a sus necesidades y maneja generalmente semillas criollas mejoradas. 
Gran productor: direcciona su cultivo a los mercados externos. Maneja un cultivo totalmente mecanizado, con altos rendimientos y mantiene una asesoría constante en diversos ámbitos.

- Sector pecuario: este eslabón forma parte de uno de los orígenes que se la da al maíz, el cual consiste en el uso exclusivo de animales. Por lo cual, algunos productores, con apoyo de grandes industriales pecuarios o gremios de la producción, están reorientando sus esfuerzos al cultivo del maíz para consumo animal.

- Industrias de alimentos balanceados: es un eslabón de alta transformación ya que el maíz se somete a un proceso de transformación nutrimental que sea adecuado para el consumo humano.

- Mayorista intermediario: realiza compras a nivel de campo y entrega a las industrias, o vende el maíz a los comerciantes detallistas.

- Comerciante detallista: este eslabón es el último de la cadena antes de llegar al consumidor final y está compuesto por varios integrantes entre ellos los supermercados, mercados populares, almacenes, vendedores ambulantes, entre otros.

- Almacenadoras (Silos): los grandes productores y las empresas multinacionales cuentan con silos, y algunos tienen fuertes vínculos con la actividad industrial de la zona.

- Agroexportadores: hasta el momento son grandes empresas multinacionales que están instaladas estratégicamente en los departamentos o que tienen directa relación con los grandes productores.

Por otro lado, cabe señalar que México sólo es representativo como productor de maíz blanco. Derivado de esto, para la descripción de la cadena de valor sólo se tomó en cuenta la producción del maíz blanco. La cual está integrada de la siguiente manera: inicia con proveedores de semilla, maquinaria y equipo, agroquímicos, servicios de capacitación y financiamiento; posteriormente, se encuentran los intermediarios que son las dependencias de gobierno que brindan apoyos en disponibilidad de semillas, investigación, capacitación, financiamiento, maquinaria y equipo, comercialización, entre otros; asimismo, los productores pueden producir para autoconsumo, para la industria harinera, a través de intermediarios o centros de acopio, o bien reabastecer a las tortillerías tradicionales. Además, la industria harinera produce para el consumo nacional y exportación hasta hacer llegar el producto al consumidor final.

Cabe destacar que, en cuanto a la industria harinera dos empresas son las más importantes en México Grupo Industrial Maseca S.A.B. de C.V. subsidiaria de Gruma, y Grupo Minsa S.A.B. de C.V., la primera tiene una participación del 71.2 por ciento del mercado, mientras que, la segunda tiene 23.5 por ciento; otras empresas productoras de harina son Harimasa con 1.4 por ciento, Cargill de México con 1.3 por ciento, Molinos Anáhuac con 1.1 por ciento y Productos Manuel José con 0.2 por ciento.

Por otro lado, con respecto a la sustentabilidad las empresas Gruma y Grupo Minsa S.A.B. de C.V. cada año reportan algunos programas y estrategias que siguen con respecto al tema. En este sentido, Gruma menciona algunos como: creando empleos para los que menos 
tienen, participa en campañas relacionadas a enfermedades como diabetes, obesidad y nutrición, así como en proporcionar alimentos para familias en extrema pobreza.

Con respecto a la gobernanza es tipo mercado, puesto que, el cambiar de proveedor representa costos nulos o bajos. Por lo que, la cooperación formal es escasa o nula. Las transacciones son simples y el mecanismo formal de gobernanza es el precio.

Figura 9. Estructura de la cadena de valor del maíz blanco en México.

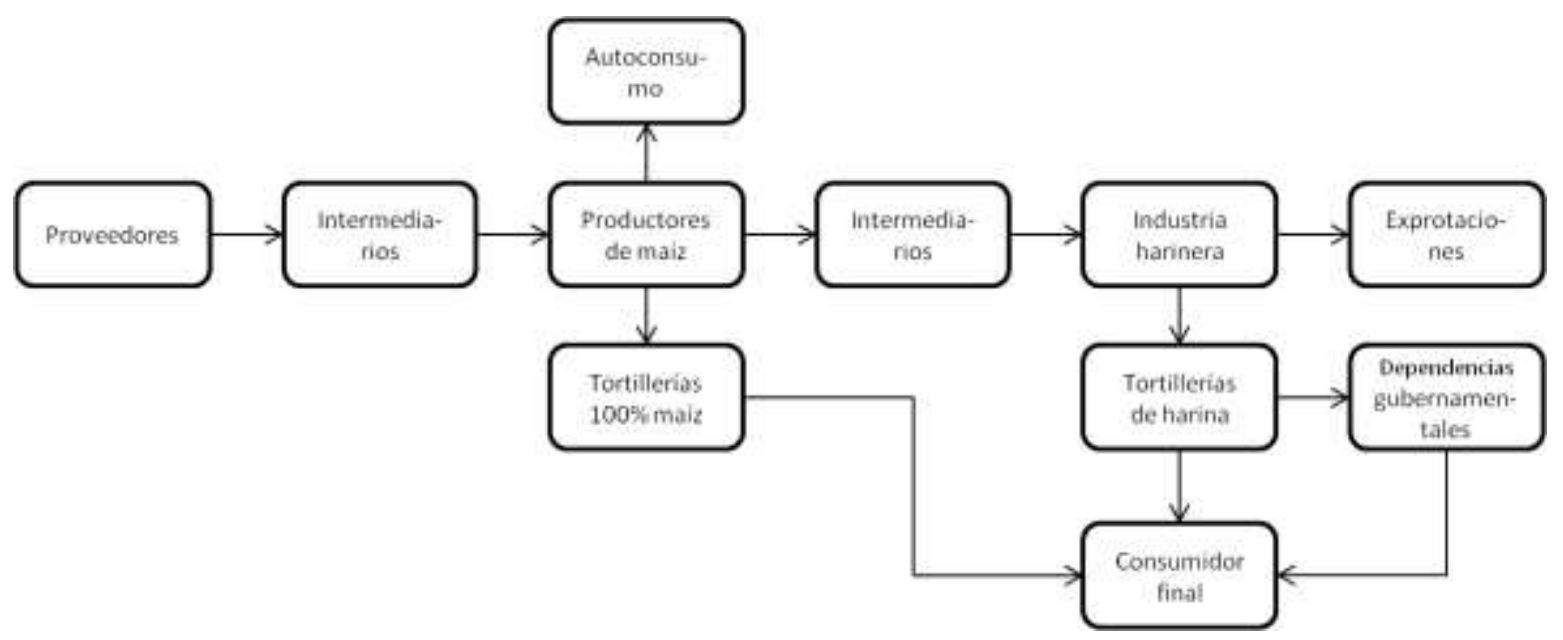

Fuente: elaboración propia.

\section{Conclusiones}

La cadena de valor del maíz presenta grandes retos para poder ser competitiva; por un lado, puede observarse el bajo rendimiento de los cultivos, y por otro, la escasez de recursos como tierra para cultivo y agua para riego. Debido a estos bajos rendimientos, los productores que cuentan con maquinaria, grandes cantidades de hectáreas para el cultivo, capacitación y recursos financieros para invertir tienen ventaja para que su negocio sea rentable. A pesar de que el gobierno ha destinado una gran cantidad de programas que atiendan las necesidades de este sector, aún sigue siendo vulnerable para poder atender la demanda del país. Existen áreas de oportunidad con respecto a la cadena de valor, principalmente en el eslabón del productor. Por lo que, es necesario impulsar políticas públicas para mejorar los rendimientos de los productos obtenidos del campo. Se necesita brindar mayor capacitación para poder establecer alianzas de negocio con los demás 
eslabones de la cadena para poder trabajar de manera integrada y que permita que ésta sea rentable. Además, la gobernanza de esta cadena es de tipo mercado, puesto que las transacciones son simples y se rigen por el precio.

\section{Bibliografía}

Deere, J. (16 de Junio de 2016). Variedades, calidad, exportaciones, producción y consumo nacional de maíz mexicano. Recuperado el 2 de Agosto de 2017, de Deere, John: https://www.deere.com.mx/es_MX/our_company/news_and_media/press_releases/2016/june/c onsumomaiz_mexicano.page

FAOSTAT. (17 de Mayo de 2017). Organización de las Naciones Unidas para la Alimentación y la Agriculatura. Recuperado el 10 de Agosto de 2017, de Organización de las Naciones Unidas para la Alimentación y la Agriculatura: http://www.fao.org/faostat/es/\#data/QC

FIRA. (2015). Panorama agroalimentario. Ciudad de México: Fideicomisos Instituidos en Relación con la Agricultura.

FIRA. (2016). Panorama agroalimentario. Ciudad de México: Fideicomisos Instituidos en Relación con la Agricultura.

Fretes, F., \& Martínez, M. (agosto de 2011). Maíz Analisis de la cadena de valor. Recuperado el 28 de julio de 2017, de Maíz Analisis de la cadena de valor: https://www.usaid.gov/sites/default/files/documents/1862/maiz.pdf

Gereffi, G., Humphrey, J., \& Sturgeon, T. (2005). The governance of global value chains. Review of International Political Economy, 78-104.

GRUMA. (26 de abril de 2017). GRUMA reporta resultados del primer trimestre del 2017. Recuperado el 27 de julio de 2017, de GRUMA reporta resultados del primer trimestre del 2017: www.gruma.com/media/669445/1q17-gruma-e.pdf

ISAAA. (2015). International Service for the Acquisition of Agri-biotech Applications. Recuperado el 8 de Agosto de 2017, de International Service for the Acquisition of Agri-biotech Applications: http://www.isaaa.org/resources/publications/briefs/51/executivesummary/default.asp

Kaplinsky, R., \& Morris, M. (2000). A handbook for value chain research. Ottawa: Centro internacional de investigación para el desarrollo.

Neven, D. (2015). Desarrollo de cadenas de valor alimentarias sostenibles. Roma: Organización de las Naciones Unidas para la Alimentación y la Agricultura.

Porter, M. (1985). Competitive Advantage: Creating and Sustaining Superior Performance. New York: Free Press, Macmillan. 
SAGARPA. (2013). Agricultura de autoconsumo. Recuperado el 2017, de Agricultura de autoconsumo:

http://www.sagarpa.gob.mx/Delegaciones/oaxaca/Paginas/Autoconsumo2013.aspx

SAgARPA. (27 de julio de 2016). Agricultura de Autoconsumo. Recuperado el 15 de agosto de 2017, de Agricultura de Autoconsumo: http://www.sagarpa.gob.mx/Delegaciones/oaxaca/Paginas/Autoconsumo2013.aspx

SAGARPA. (05 de diciembre de 2016). Aumenta producción de maíz 12.7 por ciento en cuatro años. Recuperado el 2017 de agosto de 22, de Aumenta producción de maíz 12.7 por ciento en cuatro años:

http://www.sagarpa.gob.mx/Delegaciones/nayarit/boletines/Paginas/BNSAGDIC042016.aspx

SE. (2012). Análisis de la cadena de valor maíz-tortilla: situación actual y facores de competencia local. Ciudad de México: Secretaría de Economía. 